\title{
Assessing validity of the adapted Arabic Paediatric Asthma Quality of Life Questionnaire among Egyptian children with asthma
}

\author{
R. Abdel Hai, ${ }^{7}$ E. Taher ${ }^{7}$ and M. Abdel Fattah ${ }^{2}$
}

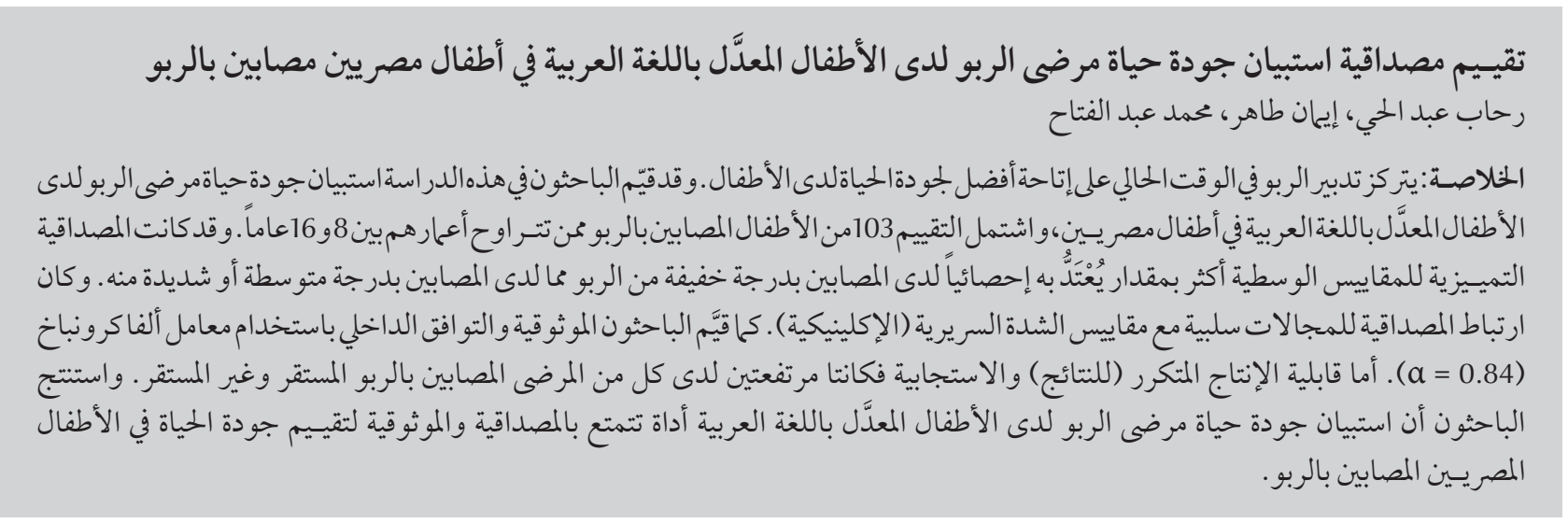

ABSTRACT The recent focus in asthma management is rendering children a better quality of life (QOL). Validity and reliability of an adapted Arabic translation of the Paediatric Asthma Quality of Life Questionnaire (PAQLQ-A) among Egyptians was assessed in a cohort of 103 asthmatic children aged 8-16 years. Discriminative validity of mean scores was significantly higher among mild asthmatics than those with moderate/severe asthma. Construct validity of domains was significantly negatively correlated with clinical severity score. Reliability and internal consistency were assessed using Cronbach alpha coefficient $(\alpha=0.84)$. Reproducibility and responsiveness were high among both stable and unstable asthma patients. PAQLQ-A is valid and reliable for assessing QOL among Egyptian asthmatic children.

Évaluation de la validité de l'adaptation en arabe du questionnaire sur la qualité de vie des enfants asthmatiques pour les enfants égyptiens asthmatiques

RÉSUMÉ Le récent intérêt accordé à la gestion de l'asthme permet d'améliorer la qualité de vie des enfants. La validité et la fiabilité d'une traduction en arabe adaptée du questionnaire sur la qualité de vie des enfants asthmatiques (PAQLQ-A) pour les enfants égyptiens a été évaluée dans une cohorte de 103 enfants asthmatiques âgés de 8 à 16 ans. La validité discriminante des notes moyennes était nettement plus élevée chez les enfants légèrement asthmatiques que chez ceux souffrant d'asthme modéré ou sévère. Une nette corrélation négative a été observée entre la validité de construit des domaines et le score de sévérité clinique. La fiabilité et la cohérence interne ont été évaluées à l'aide du coefficient alpha de Cronbach $(\alpha=0,84)$. La reproductibilité et la réactivité étaient fortes à la fois chez les patients asthmatiques stables et instables. Le PAQLQ-A est valable et fiable pour évaluer la qualité de vie des enfants égyptiens asthmatiques. 


\section{Introduction}

Globally, bronchial asthma is a major health problem especially among children, due to the increasing prevalence and associated increase in its morbidity and mortality $[1,2]$. It has recently been recognized as the most common cause of school absence, thus affecting children's educational potential and adversely affecting a child's quality of life [3]. The introduction of new and long-acting inhaled drugs has greatly improved the prognosis of asthma $[4,5]$ and nowadays the focus of concern has shifted towards improvements in children's quality of life (QOL) [6].

QOL is essentially viewed as a subjective, multidimensional experience involving summary evaluations of the positive and negative attributes characterizing one's life [7]. In children, QOL used to be based on the conventional assessment of asthma severity, the presence and intensity of symptoms, the need for medication, pulmonary function testing and discussions with parents or caregivers [8]. Conversely, evidence has shown that clinical parameters have a weak correlation with the child's emotional aspects and with his/her daily functions and expectations [9].

The Paediatric Asthma Quality of Life Questionnaire (PAQLQ) was one of the first questionnaires to be used in the assessment of QOL of asthmatic children. Juniper et al. developed the questionnaire, which was validated and published originally in English, in 1996 [10], and then translated into other languages $[11-14]$. To the authors' knowledge, the Arabic version has not previously been assessed for validity and reliability in Egypt. The aim of the present study was to assess the validity and reliability of an adapted Arabic translation of PAQLQ, in order to utilize this questionnaire in assessing the QOL in Egyptian children and adolescents with asthma.

\section{Methods}

\section{Study setting and design}

This prospective cohort study was conducted at the outpatient allergy clinic of the New Children's Hospital, University of Cairo, over a 9-month period from January to September 2006.

\section{Sample size and study participants}

Sample size calculation was conducted using the Power and Sample Size software, version 2.1.31 [15], and were based on the following inputs: power = $85 \%$, significance level $=0.05$, an equal proportion of children with mild and moderate/severe asthma, an ability to detect difference of mean scores between these 2 groups of children $=0.2$ and standard deviation $=0.5$. A sample size of 113 participants was found to fulfil these inputs.

Over a 6-month period, we enrolled a total of 110 children and adolescents aged between 8 and 16 years, who were registered and having regular follow-up at the clinic and who fulfilled the study inclusion criteria. Of these, 7 were lost to follow-up and 103 continued until the end of the study ( 31 females and 72 males), giving a participation rate of $93.6 \%$ and study power of $82.0 \%$.

The inclusion criteria were patients with intermittent or persistent asthma as defined by the Global Initiative for Asthma guidelines [16]. All patients matching these definitions who visited the clinic during the study period were included. Exclusion criteria for children were: age below 8 years or above 16 years; concomitant illnesses other than asthma that could affect QOL; suspicion of having an alternative cause for recurrent wheezing other than asthma; illiterate; or refusal to participate.

\section{Ethical considerations}

The study design and methodology was approved by the scientific research committee of the Department of Paediatrics,
Faculty of Medicine, University of Cairo. Data confidentiality was preserved throughout the study in accordance with the revised Helsinki declaration of bioethics [17]. All children, as well as their parents and/or guardians, were informed about the aims of the study. Written informed consent was obtained from the caregivers of the participants who agreed to their child's participation in the study.

\section{Data collection}

After inclusion, children were clinically evaluated and interviewed at 3 predefined dates: on entering the study, after 4 weeks and after another 4 weeks. The child's clinical condition was assessed using a clinical severity score (CSS) that Juniper et al. had utilized for the validation of the original English PAQLQ [10]. Each item of the CSS was assigned 1 point, and according to the total sum of scores $($ maximum $=$ 6), participant children were clinically classified as "mild" (score $\leq 2$ ) or "moderate/severe" asthma (score $>2$ ). Children were assigned as "stable asthma" if they remained in the same CSS group throughout the 3 visits or "unstable asthma" if they changed groups, turning from mild into moderate/severe or vice versa over the 3 visits.

The translated PAQLQ consists of 23 questions divided over 3 domains: activity limitation (5 questions), symptoms (10 questions) and emotional function (8 questions). It uses a 7-point Likert scale with higher scores indicating better health-related quality of life (HRQOL) perception. The maximum possible score for each item is 7 (good HRQOL) and the minimum score is 1 (poor HRQOL). The contribution of each item in the questionnaire to the 3 domains of activity limitation, symptoms and emotional function was evaluated by calculating the mean response to all its items for each domain. In addition, the overall score was calculated as being the average of the means of the 3 domains. The children themselves selected 
the first 3 distressing items from a list of day-to-day practice items.

Before the start of the study, the questionnaire was pre-tested in a pilot phase to 20 patients (not included in the final sample) with intermittent or persistent asthma, aged $8-16$ years, mean age 10.9 (SD 2.3) years, 12 of whom were males. After this assessment, 5 items in the original Arabic PAQLQ were removed as they did not match with the Egyptian culture (baseball, roller-boarding, skateboarding, waterskating and sand-skating). The other items were maintained according to the translation. The new adapted questionnaire was termed the Paediatric Asthma Quality of Life Questionnaire-adapted (PAQLQ-A) and the same scoring system (1-7) was maintained as that used in the original questionnaire. In all 3 visits, and after assessing the children with the CSS, they were subjected to the interviewer-administered version of the Arabic translation of the PAQLQ-A.

\section{Assessing PAQLQ-A properties}

The PAQLQ-A was assessed for its validity and reliability $[14,18-21]$. The face validity of the PAQLQ-A was previously established during the process of developing the questionnaire through a full literature review, expert opinion and patient inputs [18]. The content validity was established through the process of pre-testing and item reduction during the pilot phase. Discriminative validity was assessed by testing the significant difference between mean scores for patients with different disease severities (mild, and moderate/severe). To test construct validity the different domains of the PAQLQ-A were compared with the CSS to determine if it behaved as predicted, i.e. the higher the CSS the lower the PAQLQ-A score.

Thetestreliabilitymeasuresincluded reproducibility (evaluated in the stable asthma group at the 2 nd and $3 r d$ visits by the same observer using Spearman correlation testing); responsiveness (assessed among unstable patients by measuring the variation in the questionnaire's mean domain scores at the 2 nd and 3rd visits by the same observer); and internal consistency (measured by correlation of items within the same domain and with the overall questionnaire score using Cronbach alpha coefficient, which was set at an acceptable range of 0.70 to $0.84[22]$ ).

\section{Statistical analysis}

A pre-designed SPSS, version 11.01 file was used for data entry and analysis. The following tests were used to test adaptation and validation of the PAQLQ: chi-squared test, Student $t$-test, paired t-test, analysis of variance, Spearman correlation and Cronbach alpha reliability coefficient, with $95 \%$ confidence intervals $(95 \% \mathrm{CI})$ and significant $P$ values of $<0.05$.

\section{Results}

The age of the study participants ranged from 8 to 16 years, with a mean of 11.3 [standard deviation (SD) 1.7] years and a predominance of males (69.9\%). Almost three-quarters (72.5\%) were urban residents and the rest (27.5\%) were rural residents. At initial recruitment $56 \%$ of children suffered from moderate to severe asthma, with no statistically significant differences detected between males and females. Initially, CSS was evaluated with an overall mean score of 2.7 (SD 0.9) among all patients. Stratification by sex revealed a CSS of 2.7 (SD 0.9) in males and 2.8 (SD 0.9) in females with no significant statistical difference (Table 1).

Before applying the PAQLQ-A, patients were asked to choose the first 3 most distressing items from a list of day-to-day practice items. The most frequently chosen were: sleeping (28.2\%), playing football (16.5\%) and playing with friends (11.7\%). The initial assessment of QOL showed the mean score of the symptoms domain was 3.7 (SD 0.6), of the emotions domain was 3.9 (SD 0.6) and of the activities domain was 4.5 (SD 0.8), while the overall score was 4.0 (SD 0.5) with no statistically

\begin{tabular}{|c|c|c|c|c|}
\hline \multicolumn{5}{|c|}{$\begin{array}{l}\text { Table } 1 \text { Baseline characteristics of asthma patients and clinical severity score } \\
\text { and scores on the Paediatric Asthma Quality of Life Questionnaire-adapted } \\
\text { (PAQLQ-A) domains at the 1st visit }\end{array}$} \\
\hline \multirow[t]{2}{*}{ Baseline characteristic } & Males & Females & Total & $P$-value \\
\hline & No. (\%) & No. (\%) & No. (\%) & \\
\hline Sex & $72(69.9)$ & $31(30.1)$ & $103(100.0)$ & - \\
\hline Age group (years) & & & & $0.351^{\mathrm{a}}$ \\
\hline$<11$ & $19(26.4)$ & $11(35.5)$ & $30(29.1)$ & \\
\hline$\geq 11$ & $53(73.6)$ & $20(64.5)$ & $73(70.9)$ & \\
\hline Severity of asthma & & & & $0.814^{\mathrm{a}}$ \\
\hline Mild & $32(44.4)$ & $13(41.9)$ & $45(43.7)$ & \\
\hline \multirow[t]{2}{*}{ Moderate/severe } & $40(55.6)$ & $18(58.1)$ & $58(56.3)$ & \\
\hline & $\begin{array}{l}\text { Mean score } \\
\text { (SD) }\end{array}$ & $\begin{array}{l}\text { Mean score } \\
\text { (SD) }\end{array}$ & $\begin{array}{l}\text { Mean score } \\
\text { (SD) }\end{array}$ & \\
\hline \multicolumn{5}{|l|}{$\begin{array}{l}\text { Clinical severity and } \\
\text { PAQLQ-A domains }\end{array}$} \\
\hline Clinical severity 1st visit & $2.7(0.9)$ & $2.8(0.9)$ & $2.7(0.9)$ & $0.845^{\mathrm{b}}$ \\
\hline Symptoms, 1st visit & $3.7(0.5)$ & $3.8(0.6)$ & $3.7(0.6)$ & $0.812^{\mathrm{b}}$ \\
\hline Emotions, 1st visit & $3.8(0.6)$ & $4.0(0.7)$ & $3.9(0.6)$ & $0.781^{b}$ \\
\hline Activities, 1st visit & $4.5(0.8)$ & $4.4(0.8)$ & $4.5(0.8)$ & $0.607^{b}$ \\
\hline Overall, 1st visit & $4.0(0.6)$ & $4.1(0.5)$ & $4.0(0.5)$ & $0.298^{\mathrm{b}}$ \\
\hline
\end{tabular}

${ }^{a}$ Chi-squared test; ${ }^{b}$ Student $t$-test.

$S D=$ standard deviation . 
significant difference detected between males and females (Table 1).

During follow-up, several patients changed their asthma stability and were reclassified as stable or unstable. Thus, in the final assessment, $63 \mathrm{pa}-$ tients (61.2\%) were classified as having stable asthma, while 40 (38.8\%) were classified as unstable asthma, with no statistical difference between males and females. Throughout follow-up, gradual improvement occurred so that the percentage of patients with mild asthma increased from $43.7 \%$ initially to $67.0 \%$ in the 2 nd visit to reach $73.8 \%$ by the 3rd visit. When assessing CSS, as well as all domains of the PAQLQ-A and the overall score, a gradual significant improvement was detected over the 3 visits, with lower CSS and higher QOL domain scores (Table 2).

Assessment of the psychometric properties of the PAQLQ-A was conducted by evaluating its validity and reliability. Discriminant validity was assessed during the 1st visit and a statistically significant difference was observed between patients with mild asthma and those with moderate to severe asthma. Those suffering from the mild type showed higher mean QOL scores in all domains, in comparison with their counterparts with moderate to severe asthma (Table 3).

In terms of construct validity, the different domains of the PAQLQ-A were compared with the CSS, and a significant negative correlation was observed with each domain. This was especially evident for the symptoms and emotional function domains as well as the overall score among stable patients $(r=-0.65,-0.62$ and -0.56 in the 2 nd visit and $-0.71,-0.79$ and -0.69 at the 3rd visit respectively). Among unstable patients a similar significant negative correlation was also observed in all domains, that was evident for each of symptoms, emotions and overall score $(r=-0.55,-0.53$, and -0.55 during the

$\begin{aligned} & \text { Table 2 Comparison of clinical severity score and the Paediatric Asthma Quality } \\
& \text { of Life Questionnaire-adapted (PAQLQ-A) domains among all patients during the } \\
& \text { follow-up period }\end{aligned}$
\begin{tabular}{lcccr}
\hline $\begin{array}{l}\text { Clinical severity and } \\
\text { PAQLQ-A domains }\end{array}$ & $\begin{array}{c}\text { 1st visit } \\
\text { Mean score } \\
\text { (SD) }\end{array}$ & $\begin{array}{c}\text { 2nd visit } \\
\text { Mean score } \\
\text { (SD) }\end{array}$ & $\begin{array}{c}\text { 3rd visit } \\
\text { Mean score } \\
\text { (SD) }\end{array}$ & P-value $^{\mathrm{a}}$ \\
& $2.7(0.9)$ & $2.1(0.8)$ & $1.6(0.6)$ & 0.001 \\
Clinical severity & $3.7(0.5)$ & $4.3(0.7)$ & $4.9(0.8)$ & $<0.001$ \\
Symptoms & $3.8(0.6)$ & $4.5(0.6)$ & $5.1(0.8)$ & 0.001 \\
Emotions & $4.5(0.8)$ & $4.8(0.8)$ & $5.2(0.8)$ & $<0.001$ \\
Activities & $4.0(0.5)$ & $4.6(0.6)$ & $5.1(0.8)$ & 0.001 \\
Overall & & &
\end{tabular}

${ }^{a}$ ANOVA.

$S D=$ standard deviation . 2nd visit and $-0.73,-0.66$ and -0.73 at the 3 rd visit respectively) (Table 4).

When assessing reproducibility, stable asthma patients were compared at 2 different times: the 2 nd visit and 3rd visit with a 4-week interval between the 2 visits. A highly significant positive correlation was found in all domains between the 2 visits: symptoms ( $r=$ $0.89)$, emotions $(r=0.79)$, activities ( $r$ $=0.88)$ and overall score $(r=0.87)(P$ $<0.001)$. Assessment of responsiveness was done by comparing each domain score at 2 different times (2nd and 3rd visits) among unstable asthma patients. The results showed a statistically significant improvement in all domains $(P<$ 0.001 ), and the same occurred with the CSS (Table 5).

The reliability of the PAQLQ-A was assessed by the Cronbach alpha coefficient for all patients, as well as after ues of $0.84,0.80$ and 0.88 respectively (Table 6). Internal consistency was stratification by stability, yielding val- also assessed by Cronbach alpha for all patients, using correlations of different items within its domain, yielding values of 0.85 for symptoms, 0.83 for emotions and 0.72 for activities $(P<0.001)$ (Table 6).

\section{Discussion}

Assessing only the clinical parameters of asthma provides just one aspect of its great impact on a child's life. Growing interest in the impact of asthma on dayto-day function is leading investigators to include asthma-specific HRQOL questionnaires in a broad range of clinical studies [7]. In an earlier study conducted among Egyptian children with asthma, the burden of asthma on a child's QOL was estimated using total disabling days, and the study concluded that a child with asthma would suffer approximately 3 weeks of disrupted sleep/year and 8 weeks of disrupted waking hours/year, in addition to

Table 3 Comparison of Paediatric Asthma Quality of Life Questionnaire-adapted (PAQLQ-A) domain scores at the 1st visit, according to disease severity

\begin{tabular}{lccc} 
PAQLQ-A domains & Mild asthma patients & $\begin{array}{c}\text { Moderate/severe } \\
\text { asthma patients }\end{array}$ & P-value \\
Symptoms, 1st visit & $3.9(0.6)$ & $3.5(0.5)$ & $<0.001$ \\
Emotions, 1st visit & $4.2(0.6)$ & $3.6(0.6)$ & $<0.001$ \\
Activities, 1st visit & $4.5(0.9)$ & $4.3(0.7)$ & 0.41 \\
Overall, 1st visit & $4.2(0.5)$ & $3.8(0.5)$ & $<0.001$ \\
\hline
\end{tabular}

$S D=$ standard deviation . 


$\begin{aligned} & \text { Table } 4 \text { Correlation between clinical severity score and mean scores for each of } \\
& \text { the Paediatric Asthma Quality of Life Questionnaire-adapted (PAQLQ-A) domains } \\
& \text { at the 2nd and 3rd visits, according to stability of asthma }\end{aligned}$
\begin{tabular}{lcccc}
\hline $\begin{array}{l}\text { Clinical severity and PAQLQ-A } \\
\text { domains }\end{array}$ & Stable asthma patients & $\begin{array}{c}\text { Unstable asthma } \\
\text { patients }\end{array}$ \\
& $\boldsymbol{r}$ & $\boldsymbol{P}$-value & $\boldsymbol{r}$ & $\boldsymbol{P}$-value \\
2nd visit & & & & \\
Clinical severity $\times$ symptoms & -0.65 & $<0.001$ & -0.55 & $<0.001$ \\
Clinical severity $\times$ emotions & -0.62 & $<0.001$ & -0.53 & $<0.001$ \\
Clinical severity $\times$ activities & -0.23 & $<0.001$ & -0.27 & $<0.001$ \\
Clinical severity $\times$ overall & -0.56 & $<0.001$ & -0.55 & $<0.001$ \\
3rd visit & & & & $<0.001$ \\
Clinical severity $\times$ symptoms & -0.71 & $<0.001$ & -0.73 & $<0.001$ \\
Clinical severity $\times$ emotions & -0.78 & $<0.001$ & -0.66 & $<0.001$ \\
Clinical severity $\times$ activities & -0.31 & $<0.001$ & -0.54 & $<0.001$ \\
Clinical severity $\times$ overall & -0.69 & $<0.001$ & -0.73 & \\
\hline
\end{tabular}

$r=$ correlation coefficient.

possible maximum hospitalization and emergency room visits of 2.5 months/ year and 195 days/year respectively [23]: hence the importance of measuring QOL.

The PAQLQ is one of the most widely used instruments for measuring HRQOL in children with asthma and has been validated in many countries around the world $[11-14,24]$. When testing the validity and reliability of the adapted Arabic version of PAQLQ the questionnaire displayed a significant discriminant validity in both the symptoms and activities domains, with the exception of its discriminative ability in the emotions domain, which was weak. Moreover, the questionnaire had high construct validity with a strong significant negative correlation between CSS and the means of the 3 questionnaire domains as well as the overall score in both stable and unstable asthma groups at 2 different times. These results were comparable to the results of other studies which reported that the construct validity of their adapted questionnaire was confirmed in both cross-sectional and longitudinal studies by demonstrating a strong correlations between various PAQLQ-A domains with clinical asthma parameters (asthma diary, beta-agonist use and peak expiratory flow rate) $[14,24]$.

The reproducibility of the PAQLQ-A was assessed by applying the questionnaire to stable asthma patients at the 2 nd and 3rd visits. There was a

\begin{tabular}{|c|c|c|c|c|}
\hline $\begin{array}{l}\text { Table } 5 \text { Comparison o } \\
\text { Paediatric Asthma Qu } \\
\text { patients with unstable }\end{array}$ & $\begin{array}{l}\text { clinical sever } \\
\text { lity of Life Qu } \\
\text { asthma at the }\end{array}$ & $\begin{array}{l}\text { core and diff } \\
\text { ionnaire-ada } \\
\text { d and 3rd visi }\end{array}$ & $\begin{array}{l}\text { nt domains o } \\
\text { ed (PAQLQ-A) }\end{array}$ & ne \\
\hline Clinical severity and & 1st visit & 2nd visit & 3rd visit & $P$-value \\
\hline PAQLQ-A domains & $\begin{array}{l}\text { Mean score } \\
\text { (SD) }\end{array}$ & $\begin{array}{l}\text { Mean score } \\
\text { (SD) }\end{array}$ & $\begin{array}{l}\text { Mean score } \\
\text { (SD) }\end{array}$ & \\
\hline Clinical severity & $2.2(0.7)$ & $1.6(0.9)$ & - & $<0.001$ \\
\hline Symptoms & - & $4.4(0.7)$ & $5.1(0.9)$ & $<0.001$ \\
\hline Emotions & - & $4.7(0.7)$ & $5.1(0.9)$ & $<0.001$ \\
\hline Activities & - & $4.5(0.6)$ & $5.1(0.8)$ & $<0.001$ \\
\hline Overall & - & $4.3(0.7)$ & $5.0(0.8)$ & $<0.001$ \\
\hline
\end{tabular}

$S D=$ standard deviation . strong significant correlation between the mean overall scores in these visits. The main purpose of a QOL scale is its ability to detect important changes in a patient's QOL. Therefore, a "good" scale is one that is sensitive to change for the population under study [25]. Responsiveness was determined by studying unstable asthma patients. Comparison of the mean domain scores in the 2nd and 3 rd visits separately showed statistically significant differences, revealing that in unstable asthma patients, when the clinical status of the patient changed (improved or worsened), the questionnaire responded accordingly. Therefore the PAQLQ-A was sensitive to small but clinically significant changes in the health status and the child's daily QOL. These findings agree with other studies that assessed these aspects of the PAQLQ $[14,24]$.

The reliability and internal consistency of an instrument is accepted at a Cronbach alpha coefficient value above 0.7. Concerning the PAQLQ-A reliability, an alpha value above 0.8 was found when assessing all patients and when assessing stable and unstable asthma patients separately. Moreover, the internal consistency was established regarding each individual domain. These results are comparable to those of Reichenberg and Broberg [11], who applied the PAQLQ to Swedish children and found a Cronbach alpha coefficient of 0.92 for the overall mean score, 0.86 for the symptoms domain, 0.84 for the emotions domain and 0.79 for the activities domain. The results are also comparable to those of the Spanish study that found the alpha coefficient ranged between 0.88 and 0.96 for stable and unstable asthma patients respectively [12].

Assessing HRQOL as a proxy measure of clinical outcome considers the impact of the condition and its treatment on a child's physical, emotional and social functioning. It provides a more subjective patient-led baseline against which effects of interventions 


\begin{tabular}{|c|c|c|c|}
\hline \multirow[t]{2}{*}{ Variable } & $\begin{array}{l}\text { Single measure } \\
\text { interclass }\end{array}$ & $\begin{array}{c}\text { Average measure } \\
\text { interclass }\end{array}$ & \multirow[t]{2}{*}{$\alpha$-value } \\
\hline & Coefficient $(95 \% \mathrm{Cl})$ & Coefficient $(95 \% \mathrm{CI})$ & \\
\hline \multicolumn{4}{|l|}{ Type of asthma } \\
\hline Stable & $0.51 *(0.38-0.63)$ & $0.80 *(0.71-0.87)$ & 0.80 \\
\hline Unstable & $0.64 *(0.56-0.77)$ & $0.88 *(0.80-0.93)$ & 0.88 \\
\hline All patients & $0.57 *(0.48-0.66)$ & $0.84 *(0.78-0.89)$ & 0.84 \\
\hline \multicolumn{4}{|c|}{ PAQLQ-A domains } \\
\hline Symptoms & $0.34 *(0.27-0.42)$ & $0.85 *(0.80-0.89)$ & 0.85 \\
\hline Emotions & $0.35^{*}(0.28-0.44)$ & $0.83 *(0.77-0.87)$ & 0.83 \\
\hline Activities & $0.30 *(0.22-0.40)$ & $0.72 *(0.63-0.80)$ & 0.72 \\
\hline
\end{tabular}

${ }^{*} P<0.001$.

$C l=$ confidence interval.

can be evaluated. This can only be achieved if the measurement tool is valid, reliable, disease-specific and responsive to change [26]. The PAQLQ-A in this study has been validated among Egyptian asthmatic children from urban and rural areas with an approximately equal distribution of disease severity. It was found to be able to discriminate between levels of disease severity and to inform on minimal, yet important, clinical changes and how they affected the child's QOL.
Thus it can be used to evaluate the outcome effects of treatment.

Another positive aspects of the PAQLQ-A is that it is relatively quick and easy to use. It took from 10 to 20 minutes to be applied, depending on the child's age, intellectual capacity and education level (it was noted that the first interview usually was longer and the last one shorter). This is consistent with reports on the original and other adapted questionnaires [10-14].
One drawback of the questionnaire arises when it is applied to children 8 or 9 years old, since children at this age sometimes are not able understand the difference between certain terms, such as "mildly", "moderately" and "severely". In this case in our study, these terms were explained by the interviewer using words in Egyptian dialect in order to avoid information bias during data collection.

\section{Conclusion}

This study has confirmed the PAQLQ-A validity and reliability as a multidimensional asthma-specific and age-appropriate instrument for assessing the HRQOL of Egyptian asthmatic children and adolescents. The PAQLQ-A did not modify the properties of the original questionnaire. The adaptation of activities did not interfere with the application and properties of the original PAQLQ. We recommend its introduction and routine application when assessing QOL among Egyptian children with asthma.

\section{References}

1. Lee TA et al. Agreement between caregiver reported healthcare utilization and administrative data for children with asthma. Journal of asthma, 2007, 44(3):189-94.

2. Rance K, Trent SA. Profile of a primary care practice asthma program. Journal of pediatric health care, 2005, 19(1):25-32.

3. Ramos-Barbón D. Asma [Asthma]. Archivos de bronconeumología, 2007, 43(Suppl. 2):3-14.

4. Baena-Cagnani CE et al. New perspectives in the treatment of allergic rhinitis and asthma in children. Current opinion in allergy and clinical immunology, 2007, 7(2):201-6.

5. Blaiss MS, Hill B. Outcomes in pediatric asthma. Current allergy and asthma reports, 2005, 5(6):431-6.

6. Baiardini I et al. Allergic diseases and their impact on quality of life. Annals of allergy, asthma and immunology, 2006, 97(4):419-28.

7. Eiser C, Morse R. Quality of life measures in chronic diseases of childhood. Health technology assessment, 2001, 5(4):1-7.

8. Van Gent R et al. Quality of life in children with undiagnosed and diagnosed asthma. European journal of pediatrics, 2007, 166(8):843-8.

9. Upton $\mathrm{P}$ et al. Measurement properties of the UK-English version of the Pediatric Quality of Life Inventory 4.0 (PedsQL) generic core scales. Health and quality of life outcomes, 2005, 1(3):22.

10. Juniper EF et al. Measuring quality of life in children with asthma. Quality of life research, 1996, 5:35-46.

11. Reichenberg K, Broberg AG. Quality of life in childhood asthma: use of the Paediatric Asthma Quality of Life Questionnaire in a Swedish sample of children 7 to 9 years old. Acta paediatrica, 2000, 89:989-95.

12. Badia $X$ et al. Validacion de la version espanola del Pediatric Quality of Life Questionnaire en la valoracion de la calidad de vida del nino asmatico [Validity of the Spanish version of the Pediatric Quality of Life Questionnaire for evaluating quality of life in asthmatic children]. Medicina clínica, 2001, 116(15):565-72.

13. Clarke E et al. Pediatric asthma quality of life questionnaire: validation in children from Singapore. Asian Pacific journal of allergy and immunology, 1999, 17(3):155-61.

14. Raat $\mathrm{H}$ et al. Responsiveness, longitudinal- and cross-sectional construct validity of the Pediatric Asthma Quality of Life Questionnaire (PAQLQ) in Dutch children with asthma. Quality of life research, 2005, 14(1):265-72.

15. PS: Power and Sample Size Calculation. Department of Biostatistics, Vanderbilt University [freeware] (http://biostat. 
mc.vanderbilt.edu/twiki/bin/view/Main/PowerSampleSize, accessed 31 August 2009).

16. GINA report. Global strategy for asthma management and prevention. Revised 2006. Global Initiative for Asthma [online document] (http://www.ginasthma.org, accessed 12 August 2009).

17. World Medical Association Declaration of Helsinki. Ethical principles for medical research involving human subjects. Revised by the 52nd WMA General Assembly, Edinburgh, Scotland, October 2000 (http://www.wma.net/e/policy/b3.htm, accessed 12 August 2009).

18. Juniper EF. How important is quality of life in pediatric asthma? Pediatric pulmonology. Supplement, 1997, 15:17-21.

19. Oleson M. Content validity of the Quality of Life Index. Applied nursing research, 1990, 3(3):126-7.

20. Hays RD, Anderson RT, Revicki D. Assessing reliability and validity of measurement in clinical trials. In: Staquet MJ, Hays RD, Fayers PM, eds. Quality of life assessment in clinical trials. Oxford, Oxford University Press, 1998:169-82.
21. French DJ, Christie MJ, Sowden AJ. The reproducibility of the Childhood Asthma Questionnaires: measures of quality of life for children with asthma aged 4-16 years. Quality of life research, 1994, 3(3):215-24.

22. Cronbach LJ. Coefficient alpha and the internal structure of tests. Psychometrika, 1951, 16(3):297-334.

23. Abdel Hai R. Bronchial asthma: a study among attendants of children's hospital, Cairo University [MSc thesis]. Cairo, Egypt, Department of Public Health, Faculty of Medicine, Cairo University, 2000.

24. Poachanukoon O et al. Pediatric Asthma Quality of Life Questionnaire (PAQLQ): validation among asthmatic children in Thailand. Pediatric allergy and immunology, 2006, 17(3):20712.

25. Hyland ME. A brief guide to the selection of quality of life instruments. Health and quality of life outcomes, 2003, 1:24.

26. Bowling A. Evaluating health services: multidisciplinary collaboration. In: Research methods in health: investigating health and health services, 2nd ed. Buckingham, UK, Open University Press, 2003.

\section{Corrections}

Hepatitis $B$ and $C$ viral infection: prevalence, knowledge, attitude and practice among barbers and clients in Gharbia governorate, Egypt. S. Shalaby, ${ }^{1}$ I.A. Kabbash, ${ }^{1}$ G. El Saleet, ${ }^{1}$ N. Mansour, ${ }^{1}$ A. Omar ${ }^{1}$ and A. El Nawawy ${ }^{2}$. Eastern Mediterranean health journal, 2010, 16(1):10-17.

The authors' affiliations should read:

${ }^{1}$ Department of Public Health, Social and Preventive Medicine, University of Tanta, Tanta, Egypt (Correspondence to S. Shalaby: shalabys@gmail.com).

${ }^{2}$ Department of Public Health and Community Medicine, Al-Azhar University, Cairo, Egypt.

Nosocomial infections in a neonatal intensive care unit in south-western Saudi Arabia. A.A. Mahfouz, T.A. Al-Azraqi, F.I. Abbag, M.N. Al-Gamal, S.Seef and C.S. Bello. Eastern Mediterranean health journal, 2010, 16(1):40-4.

In the Arabic abstract, the first sentence should read:

قاست دراسة أترابية وقوع عو امل الاختطار لعدوى المستشفيات في وحدة الرعاية المركزة للولدان في مستشفى أبها العام، بالمملكة العربية 